\title{
Multi-criteria mathematical model of the pilot training process
}

\author{
Marta Woch ${ }^{1, *}$, Józef Żurek ${ }^{2, * *}$, and Justyna Tomaszewska ${ }^{3, * * *}$ \\ ${ }^{1}$ Faculty of Cybernetics, Military University of Technology, Warsaw, Poland \\ ${ }^{2}$ Air Force Institute of Technology, Warsaw, Poland \\ ${ }^{3}$ Faculty of Aviation, Polish Air Force Academy, Dȩblin, Poland
}

\begin{abstract}
In most NATO countries, helicopter pilots are prepared in accordance with a modern system of threestage training: selection, basic and advanced. The training in the air is performed according to the parallelism of the training. The scheduling of pilot training process based on parallel model, which includes the technological relationships between the individual exercises, whereby for each air exercise, the exercises are specified, which must be done beforehand.

The purpose of this contribution is to propose a multi-criteria mathematical model which would enable the selection of exercises for each pilot, the appropriate selection of the aircraft and the moment of beginning of each exercise, so that all required exercises will be carried out in the shortest possible time and the number of trained, in a state of readiness pilots, should be as high as possible. Additionally, in this paper the sketch of a multi-criteria solution is presented. A crucial feature of this work is the model application to optimize pilot training.
\end{abstract}

\section{Introduction}

The practical training in the air is performed according to the parallelism of the training, which describes the technological relationships between the individual exercises. For each exercise, the exercises are specified, which must be done beforehand [1]. There is a possibility of repeating previously performed exercises, which is more suitable to reflect the real problem occurring in Military Units. The duration of each exercise is fixed and different types of aircraft are at the disposal.

The commander has at his disposal different types of aircrafts [2]. For each type, the number of aircraft shall be determined. Exercises are only possible on the appropriate type of aircraft. Exercises can be performed on exactly one aircraft by one pilot. A single aircraft allows one pilot to be trained in a single exercise [3]. The purpose of this contribution is to propose a mathematical model which would enable the selection of exercises for each pilot, the appropriate selection of the aircraft and the moment of beginning of each exercise, so that all required exercises are carried out in the shortest possible time. Developing a mathematical model, an additional optimisation criterion will be the number of trained, in a state of readiness pilots, which should be as high as possible.

Additionally, in this paper the sketch of a multi-criteria solution is presented. This contribution stands at the beginning of research thesis on optimization of aviation pilot training process and subsequent development will be the subject of future papers.

\footnotetext{
*e-mail: marta.woch@itwl.pl

**e-mail: jozef.zurek@itwl.pl

***e-mail: j.tomaszewska@wsosp.pl
}

\subsection{Schedule of training in helicopters}

The programme of aviation training in helicopters in the Polish Armed Forces of the Republic of Poland standardizes the process of training of flying personnel in helicopters and constitutes the basis for developing a longterm plan of air training for flights used for combat operations $[4,5]$. The block graphics of the parallelism of pilot training process is presented in figure 1. It is an example of the implementation of the scope of training. Example of schematic sequence of pilot training process for one module is presented in the following figure 2 .

\section{The sketch of the mathematical model}

\subsection{Mathematical description of the essential attributes}

$N \in \mathbb{P}$ - the number of pilots,

$C \in \mathbb{P}$ - the number of exercises,

$a_{i j}=\left\{\begin{array}{cc}1 & \text { if exercise no. } j \text { requires exercise no. } i \\ 0 & \text { otherwise }\end{array}\right.$

$i, j=\overline{1, C}$,

$b_{c}^{n}=\left\{\begin{array}{cc}1 & \text { if pilot no. } n \text { has to perform exercise no. } c \\ 0 & \text { otherwise }\end{array}\right.$

$c=\overline{1, C}, n=\overline{1, N}$,

$H \in \mathbb{P}$ - the number of aircraft types,

$S P_{h} \in \mathbb{P}$ - the number of aircraft of type $h$,

$h=\overline{1, H}$,

$d_{c} \in \mathbb{R}_{0}^{+}$- the duration of exercise no. $c, c=\overline{1, C}$,

$e_{c}^{h}=\left\{\begin{array}{cc}1 & \text { if the aircraft type } h \text { may be used } \\ 0 & \text { for the exercise } c \\ \text { otherwise }\end{array}\right.$ 


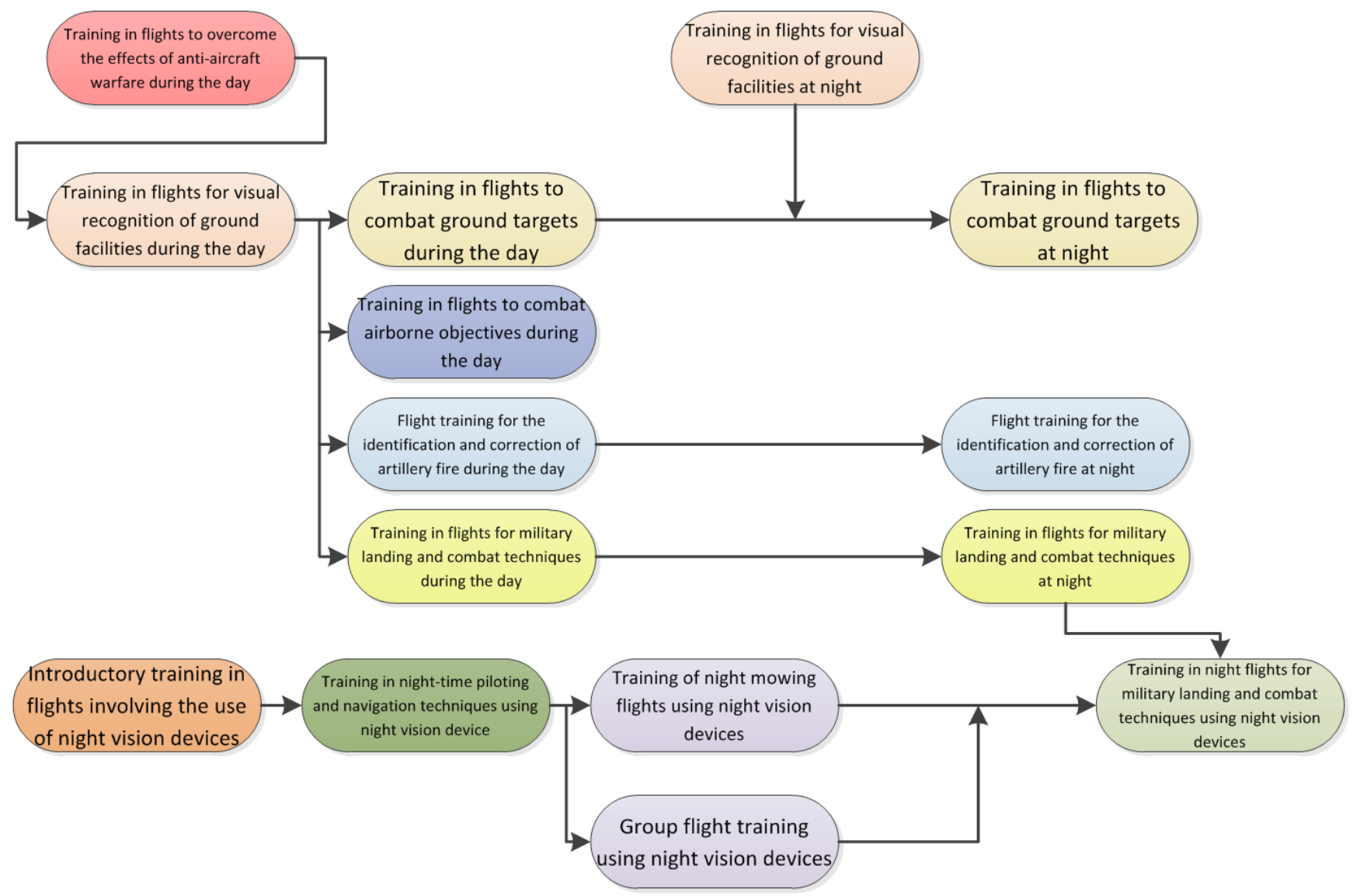

Figure 1. Sketch of the parallelism of pilot training process [4]

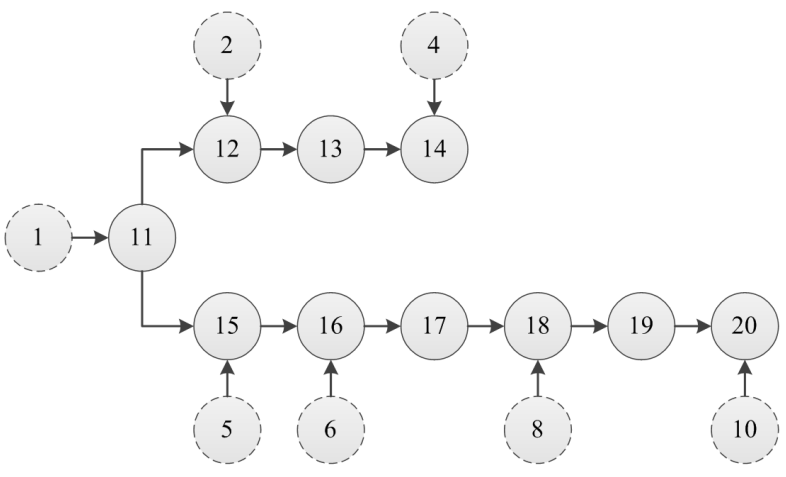

Figure 2. Example of schematic sequence of of pilot training process for one module [4]

$$
h=\overline{1, H}, c=\overline{1, C} \text {, }
$$

$$
f_{c}^{n}=\left\{\begin{array}{cc}
1 & \text { if pilot no. } n \text { has performed } \\
0 & \text { the exercise no. } c \\
\text { otherwise }
\end{array} \quad c=\overline{1, C},\right.
$$

$n=\overline{1, N}$,

$K_{n} \in \mathbb{P}$ - the number of exercises to be carried out by pilot no. $n$,

$$
\begin{gathered}
v g_{n c}=\left\{\begin{array}{cc}
1 & \text { if pilot no. } n \text { has to perform exercise no. } c \\
0 & \text { in order to be in the state of readiness } \\
\text { otherwise }
\end{array}\right. \\
x_{n k}^{h}=\overline{1, C}, n=\overline{1, N}, \quad \begin{array}{cc}
\text { if it is planned that } k \text { th in turn exercise } \\
1 & \text { will be performed by pilot no. } n \\
0 & \text { using aircraft of type } h \\
0 & \text { otherwise }
\end{array}
\end{gathered}
$$$$
n=\overline{1, N}, h=\overline{1, H}, k=\overline{1, K_{n}} \text {, }
$$

$v_{n k} \in \mathbb{P}$ - the number of the $k$ th consecutive exercise performed by pilot no. $n, k=\overline{1, K_{n}}, n=\overline{1, N}$,

$y_{k}^{n} \in \mathbb{R}^{+}$- the moment when $k$ th in turn exercise begins by pilot no. $n, n=\overline{1, N}, k=\overline{1, K_{n}}$,

$Z \in \mathbb{R}_{0}^{+}$- the duration of all training [6],

$N G \in \mathbb{P}$ - the number of qualified pilots in a state of readiness [7].

\subsection{Mathematical description of the relevant relationships between attributes}

1. Each pilot may perform the exercise only on the type of aircraft appropriate for the particular exercise:

$$
\underset{n=\overline{1, H}}{\forall} \underset{h=\overline{1, H}}{k} \underset{k=\overline{1, K_{n}}}{c}=\overline{\overline{1, C}} x_{n k}^{h} \leq e_{c}^{h}
$$

2. The starting moment of each subsequent exercise shall not be less than the sum of the starting mo- 
ment of the preceding exercise and the duration of the preceding exercise:

$$
\begin{aligned}
& {\left[\left(\sum_{h=1}^{H} x_{n k}^{h}=1\right) \wedge\left(\sum_{h=1}^{H} x_{n k+1}^{h}=1\right)\right]} \\
& \Rightarrow\left(y_{k}^{n}+d_{v_{n k}} \leq y_{k+1}^{n}\right)
\end{aligned}
$$

3. If the exercise no. $k+1$ was carried out after exercise no. $k$ by pilot $n$, exercise $k$ also had to be planned or performed by pilot $n$ :

$$
\left[\begin{array}{l}
\left.\left(a_{v_{n k} v_{n k+1}}=1\right) \wedge\left(\sum_{h=1}^{H} x_{n k+1}^{h}=1\right)\right] \Rightarrow \\
{\left[\left(\sum_{h=1}^{H} x_{n k}^{h}=1\right) \vee\left(f_{v_{n k}}^{n}=1\right)\right]}
\end{array}\right.
$$

4. The duration of all trainings should not be less than the moment of the end of each planned exercise:

$$
Z \geq\left(y_{k}^{n}+d_{v_{n k}}\right), \quad n=\overline{1, N}, k \in \mathbb{P}
$$

5. No more aircraft can be used during the exercise than are available [8-10]:

$$
\underset{h=\overline{0, H}}{\forall} \underset{t \geq 0}{\forall} \sum_{k=1}^{K}\left|\begin{array}{l}
n=\overline{1, N}: \\
\left(y_{k}^{n} \leq t \leq y_{k}^{n}+d_{v_{n k}} \wedge\right. \\
\left.\wedge x_{n k}^{h}=1\right)
\end{array}\right| \leq S P_{h}
$$

6. For each exercise, exactly one single Aircraft is used:

$$
\underset{n=\overline{1, N}}{\forall} b_{v_{n k}}^{n}=1 \Rightarrow \sum_{h=1}^{H} x_{n k}^{h}=1
$$

7. In accordance with the training schedule, an exercise with an earlier number may not require the realization of an exercise with an later number:

$$
\underset{i \geq j}{\forall} a_{i j}=0
$$

8. If the $k+1$ exercise is scheduled, its number depends on the numbers of the previous exercises according to the $A\left[a_{i j}\right]$ matrix [11]:

$$
\underset{n=\overline{1, N}}{\forall} \frac{\forall}{1, K_{n}} a_{v_{n k} v_{n k+1}}=1
$$

9. The duration of all training courses should be kept to a minimum:

$$
Z_{\left\langle K_{n},\left[x_{n k}^{h}\right]_{N \times K \times H},\left[v_{n k}\right]_{N \times K},\left[y_{k}^{n}\right]_{N \times K}\right\rangle} \min
$$

10. The number of trained, on standby pilots should be as high as possible:

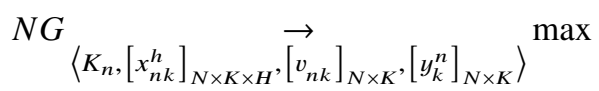

11. The number of trained, on standby pilots depends on the exercises that the pilot has to complete in order to be able to be on standby. If all the exercises required for the pilot to be in standby mode have been completed, then the pilot will be in standby mode:

$$
N G=\sum_{n=1}^{N} \prod_{c=1}^{C}\left[v g_{n c} \Rightarrow f_{c}^{n}\right]
$$

\subsection{The division of the characteristics into decision variables, criteria and data}

List of data:

$$
\begin{aligned}
& g=\left\langle N, C,\left[a_{i j}\right]_{i=\overline{1, C}, j=\overline{1, C}},\left[b_{c}^{n}\right]_{c=\overline{1, C}, n=\overline{1, N}}, H,\right. \\
& \left\langle S P_{h}\right\rangle_{h=\overline{1, H}},\left\langle d_{c}\right\rangle_{c=\overline{1, C}},\left[e_{c}^{h}\right]_{c=\overline{1, C}, h=\overline{1, H},}, \\
& {\left[f_{c}^{n}\right]_{c=\overline{1, C}, n=\overline{1, N}},\left[v g_{n c}\right]_{c=\overline{1, C}, n=\overline{1, N}\rangle}}
\end{aligned}
$$

List of decision variables:

$$
q=\left\langle\left[x_{n}^{c h}\right]_{N \times C \times H},\left[y_{c}^{n}\right]_{N \times C}, Z, N G\right\rangle
$$

Criterion:

$$
Z, N G
$$

\subsection{Analysis of the information content}

The decision-maker will know the values of all the data. The decision-maker will not know the values of the following attributes [12]:

- $Z$ - the duration of all training, as this is the result of decisions taken,

- $N G$ - the number of qualified pilots in a state of readiness, as this is the result of decisions taken,

- $K_{n}$ - the number of exercises to be carried out by pilot no. $n$, since it is a decision that decision-maker wishes to be taken,

- $x_{n k}^{h}=\left\{\begin{array}{cc} & \begin{array}{c}\text { if it is planned that } k \text { th in turn exercise } \\ 1 \\ \text { will be performed by pilot no. } n \\ \text { using aircraft of type } h \\ 0\end{array} \\ \text { otherwise }\end{array}\right.$ $n=\overline{1, N}, h=\overline{1, H}, k=\overline{1, K_{n}}$, since it is a decision that decision-maker wishes to be taken.

- $y_{c}^{n} \in \mathbb{R}_{0}^{+}$- the moment when exercise no. $c$ begins by pilot no. $n, c=\overline{1, C}, n=\overline{1, N}$, since it is a decision that decision-maker wishes to be taken.

- $y_{c}^{n} \in \mathbb{R}_{0}^{+}$- the moment when exercise no. $c$ begins

\subsection{Definition of sets of correct values, limit values for decision variables and possible criteria values}

The set of correct data values may be defined as follows:

$$
\begin{aligned}
& G=\left\{\left\langleN, C,\left[a_{i j}\right]_{i=\overline{1, C}, j=\overline{1, C}},\left[b_{c}^{n}\right]_{c=\overline{1, C}, n=\overline{1, N}}, H,\right.\right. \\
& \left\langle S P_{h}\right\rangle_{h=\overline{1, H}},\left\langle d_{c}\right\rangle_{c=\overline{1, C}},\left[e_{c}^{h}\right]_{c=\overline{1, C}, h=\overline{1, H}},\left[f_{c}^{n}\right]_{c=\overline{1, C}, n=\overline{1, N}}, \\
& \left.\left[v g_{n c}\right]_{c=\overline{1, C}, n=\overline{1, N}}\right\rangle \in \mathbb{P} \times \mathbb{P} \times \mathscr{B}^{C \times C} \times \mathscr{B}^{C \times N} \times \mathbb{P} \times \mathbb{P}^{H} \times \\
& \left.\times\left(\mathbb{R}_{0}^{+}\right)^{C} \times \mathscr{B}^{C \times H} \times \mathscr{B}^{C \times N} \times \mathscr{B}^{C \times N}:\left(\underset{i \geq j}{\forall} a_{i j}=0\right)\right\}
\end{aligned}
$$

A set of acceptable values for decision variables is as follows: 
form of the norm, related in this paper to the parameter $p$

$\begin{array}{ll}\Omega(g)=\left\{\left\langle\left[K_{n}\right]_{N},\left[x_{n k}^{h}\right]_{N \times K \times H},\left[v_{n k}\right]_{N \times K},\left[y_{k}^{n}\right]_{N \times K}, Z, N G\right\rangle^{[20-22] .}\right. & \text { The Pareto cone is defined by the expression: } \\ \in(\mathbb{P})^{N} \times \mathscr{B}^{N \times K \times H}(\mathbb{P})^{N \times K} \times\left(\mathbb{R}_{0}^{+}\right)^{N \times K} \times \mathbb{R}_{0}^{+} \times \mathbb{P}: & \Lambda=\left\{\left(\lambda_{1}, \ldots, \lambda_{n}, \ldots, \lambda_{N}\right) \in \mathbb{R}^{N} \mid \lambda_{n} \leq 0, n \in \mathbb{N}\right\}\end{array}$

$\left(\underset{n=1, N}{\forall} \underset{h=\overline{1, H}}{\forall} \underset{k=1, K}{\forall} \underset{c=\overline{1, C}}{\forall} x_{n k}^{h} \leq e_{c}^{h}\right)^{\wedge}$

$\left\{\left[\left(\sum_{h=1}^{H} x_{n k}^{h}=1\right) \wedge\left(\sum_{h=1}^{H} x_{n k+1}^{h}=1\right)\right] \Rightarrow\left(y_{k}^{n}+d_{v_{n k}} \leq y_{k+1}^{n}\right)\right\} \wedge$

$\wedge\left\{\left[\left(a_{v_{n k} v_{n k+1}}=1\right) \wedge\left(\sum_{h=1}^{H} x_{n k+1}^{h}=1\right)\right] \Rightarrow\right.$

$\left.\Rightarrow\left[\left(\sum_{h=1}^{H} x_{n k}^{h}=1\right) \vee\left(f_{v_{n k}}^{n}=1\right)\right]\right\} \wedge$

$\wedge\left[\underset{h=\overline{0, H}}{\forall} \underset{t \geq 0}{\forall} \sum_{k=1}^{K_{n}} \mid\left[n=\overline{1, N}:\left(y_{k}^{n} \leq t \leq y_{k}^{n}+d_{v_{n k}} \wedge\right.\right.\right.$

$\left.\left.\wedge x_{n k}^{h}=1\right) \mid \leq S P_{h}\right] \wedge N G=\sum_{n=1}^{N} \prod_{c=1}^{C}\left[v g_{n c} \Rightarrow f_{c}^{n}\right] \wedge$

$\wedge\left({ }_{n=\overline{1, N}}^{\forall} b_{v_{n k}}^{n}=1 \Rightarrow \sum_{h=1}^{H} x_{n k}^{h}=1\right) \wedge$

$\left.\wedge\left(\underset{n=\overline{1, N}}{\forall} \underset{k=1, K_{n}}{\forall} a_{v_{n k} v_{n k+1}}=1\right)\right\}$

\subsection{Draft formulation of the optimization task}

For data $g \in G$ determine such $q^{*}=$ $\left\langle K^{*},\left[\begin{array}{c}x^{* h}{ }_{n k} \\ \left.]_{N \times K \times H},\left[v^{*}{ }_{n k}\right]_{N \times K},\left[y_{k}^{* n}\right]_{N \times K}\right\rangle \in \Omega(g) \text { that }\end{array}\right.\right.$ $Z\left(q^{*}\right)=Z^{*}=\left\langle K_{n},\left[x^{h}\right] \min _{[v} \quad Z\right.$ and

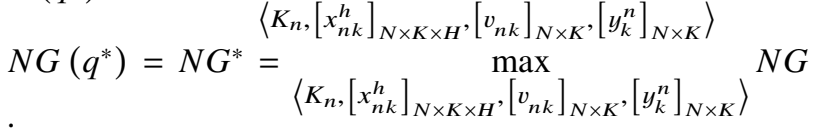

\subsection{A function to assess the achievement of the aim}

A function to assess the achievement of the aim is presented in the following form [13]:

$$
F(q)=\left(F_{1}(q), F_{2}(q)\right)=y \in \mathbb{R}^{2}, q \in \Omega(g)
$$

where:

$$
\begin{aligned}
& F_{1}(q)=-Z \text { is the maximising function, } \\
& F_{2}(q)=N G \text { is the maximising function. }
\end{aligned}
$$

\section{A sketch of a multi-criteria solution}

This task may be qualified as a task of the following type $(X, F, M(P))[14,15]$ where the collection $X$ corresponds to the collection $\Omega(g)$, a function to assess the achievement of the aim $F$ is presented as $F(q)$ and the decision preference model $M(P)$ is maximisation, indicated in literature $[16,17]$ as ' $\geq$ '.

The proposed method of resolving the problem may be a compromise method, as the decision-maker is only interested in one, any solution that is not dominated. In addition to providing a non-dominant solution, the compromise method also allows for a solution that is "biased" and has interesting practical interpretations $[18,19]$. An important problem is the question of choosing a specific which, for the optimisation sentence under consideration, will take the form of:

$$
\Lambda=\left\{\left(\lambda_{1}, \lambda_{2}\right) \in \mathbb{R}^{2} \mid \lambda_{1} \leq 0, \lambda_{2} \leq 0\right\}
$$

The Pareto-dominance relation is defined by $R=$ ' $\geq$ ' $\subset \mathbb{R}^{2} \times \mathbb{R}^{2}$.

The formula of preferences $\varphi(y, z)$ was adopted in the form of $\varphi(y, z)={ }^{\prime} y_{1} \geq z_{1}, y_{2} \geq z_{2}$ ', therefore, this is the task of maximizing the two-criterion solution.

Distance from the template, being an aggregate measure of the quality of the elements $y \in Y$ can be defined by:

$$
R_{p}^{y^{*}}(y)=\left\|y^{*}-y\right\|_{p}=\left(\sum_{n=1}^{N}\left(\left|y_{n}^{*}-y_{n}\right|\right)^{p}\right)^{1 / p}, p \geq 1
$$

The compromise solution with parameter $p=2$ consists in finding such an element $q^{*} \in \Omega(g)$, that:

$$
\left\|y^{*}-F\left(q^{*}\right)\right\|_{2}=\inf _{q \in \Omega(g)}\left\|y^{*}-F(q)\right\|_{2}
$$

where:

$\|\cdot\|_{2}$ is the Euclidean metric defined as $R_{2}^{y^{*}}(y)=$ $\sqrt{\sum_{n=1}^{N}\left(y_{n}^{*}-y_{n}\right)^{2}}$ for $N=2$

$y^{*}=\left(y_{1}^{*}, y_{2}^{*}\right)$ is the ideal point with coordinates $y_{1}^{*}=$ $\sup _{q \in \Omega(g)} F_{1}(q)$, $q \in \Omega(g)$

$y_{2}^{*}=\sup _{q \in \Omega(g)} F_{2}(q)$ for tasks of type $(X, F, \geq)$, which are suitable for describing the problem under consideration.

\section{Conclusions}

In the presented article the model of the training of the pilots is described. The multi-criteria model is based on the current instructions and programmes, which are implemented in Polish Army. Additionally, the algorithm is described, which allows to find the best order of making the exercises. A sketch of a multi-criteria solution was described in this paper as one of the examples of achieving the results.

This contribution stands at the beginning of research thesis on optimization of aviation pilot training process and subsequent development will be the subject of future papers. The content of this paper, introducing a multicriteria primary mathematical model for pilot training process, is the second paper of the series.

The key feature of the model, is the use of a prediction function to optimize the training of the pilots. Planed simulation studies, as well as comparison with data collected in Polish Air Force Academy, will give the information, if the model can be used in the process of planning the training, or should be optimized. 


\section{References}

[1] H. Tomaszek, M. Jansztal, M. Zieja, Application of the Paris formula with $m=2$ and the variable load spectrum to a simplified method for evaluation of reliability and fatigue life demonstrated by aircraft components, in Eksploatacja i Niezawodnosc Maintenance and Reliability (2013), Vol. 15(4), pp. 297-303

[2] Z. Vintr, D. Valis, A Tool for Decision Making in KOut-of- $N$ System Maintenance, in Mechanical and Aerospace Engineering, ICMAE2011 (Trans Tech Publications, 2012), Vol. 110 of Applied Mechanics and Materials, pp. 5257-5264

[3] V.Y. Kozhevnikov, A.V. Kozyrev, N.S. Semeniuk, A.V. Batrakov, V.M. Karaban, D.S. Kosov, Design and diagnostics of arc-resistant electronics for satellite telecommunication systems, in 2016 18th Mediterranean Electrotechnical Conference (MELECON) (2016), pp. 1-5

[4] Dowództwo Sił Powietrznych , Program szkolenia lotniczego na śmigłowcach w lotnictwie sit zbrojnych Rzeczypospolitej Polskiej (Warszawa, 2012)

[5] V.Y. Kozhevnikov, N. Semeniuk, A.V. Kozyrev, V.M. Karaban, D.S. Kosov, Novel automated software system for arcing simulation in spacecraft on-board electronics, in 2017 2nd International Conference on System Reliability and Safety (ICSRS) (2017), pp. 469-473

[6] Z. Vintr, D. Valis, Vehicle maintenance process optimization using life cycle costs data and reliabilitycentered maintenance, in Proceedings of the First International Conference on Maintenance Engineering (2006), pp. 180--188

[7] M. Hinz, F. Hienzsch, S. Bracke, Detection of Distinctions in Car Fleets Based on Measured and Simulated Data, in RAMS 2017-63rd Annual Reliability and Maintainability Symposium (Orlando, Florida, U.S.A., 2017)

[8] Z. Vintr, D. Valis, Modeling and Analysis of the Reliability of Systems with One-shot Items, in 2007 Annual Reliability and Maintainability Symposium (2007), pp. 380-385, ISSN 0149-144X

[9] A. Mueller, M. Hinz, S. Bracke, Optimization of the dental implant testing based on FEM simulation of fatigue and accelerated life, in Risk, Reliability and Safety: Innovating Theory and Practice (Glasgow, Scotland, 2017), pp. 16-22

[10] H. Tomaszek, M. Jansztal, M. Zieja, A simplified method to assess fatigue life of selected structural components of an aircraft for a variable load spectrum, in Eksploatacja i Niezawodnosc - Maintenance and Reliability (2011), Vol. 4(52), pp. 29-34
[11] J. Zurek, Z. Smalko, M. Zieja, Methods applied to identify causes of air events, in Reliability, Risk And Safety: Theory And Applications vols 1-3 (2010), Vol. 1-3, pp. 1817-1822

[12] A.V. Kozyrev, V.Y. Kozhevnikov, N.S. Semeniuk, L.A. Zyulkova, Theoretical Simulation of a Gas Breakdown Initiated by External Plasma Source in the Gap With Combined Metal-Dielectric Electrodes, in IEEE Transactions on Plasma Science (2015), Vol. 43, pp. 2294-2298, ISSN 0093-3813

[13] M. Zieja, M. Ważny, S. Stępien, Distribution determination of time of exceeding permissible condition as used to determine lifetimes of selected aeronautical devices/systems, in Eksploatacja i Niezawodnosc - Maintenance and Reliability (2016), Vol. 18(1), pp. 57-64

[14] A. Ameljańczyk, Teoria gier i optymalizacja wektorowa (Wydział Wydawniczy WAT, Warszawa, 1980)

[15] D. Tloczynski, Security as a determinant of choice of air transport service and air carrier on the basis of research, in Scientific Journal of Silesian University of Technology-Series Transport (2017), Vol. 95, pp. 213-222

[16] A. Ameljańczyk, Optymalizacja wielokryterialna (Wydział Wydawniczy WAT, Warszawa, 1982)

[17] B. Babiarz, Reliability analysis in subsystem of heat supply, in 2016 International Conference on Information and Digital Technologies (IDT), edited by IEEE (Rzeszow, Poland, 2016), pp. 11-16

[18] A. Ameljańczyk, Elementy optymalizacji wielokryterialnej. Zeszyt 2. Wybrane metody rozwiazania (Wyktady na studium doktranckim) (Wydział Wydawniczy WAT, Warszawa, 1981)

[19] M. Hinz, F. Hienzsch, S. Bracke, Development of two methods for the characterisation of an automotive fleet behaviour based on the simulation of single car rides, in Risk, Reliability and Safety: Innovating Theory and Practice (Glasgow, Scotland, 2017), pp. 1593-1598

[20] M. Zieja, M. Ważny, S. Stępien, Outline of a method for estimating the durability of components or device assemblies while maintaining the required reliability level, in Eksploatacja i Niezawodnosc - Maintenance and Reliability (2018), Vol. 20(2), pp. 260266

[21] B. Babiarz, A. Blokus-Roszkowska, Probabilistic model of district heating operation process in changeable external conditions, in Energy and Buildings (2015), Vol. 103, pp. 159-165

[22] B. Babiarz, K. Chudy-Laskowska, Forecasting of failures in district heating systems, in Engineering Failure Analysis (2015), Vol. 56, pp. 384-395 